\title{
Neonatal and Pediatric Manual Hyperinflation: Influence of Oxygen Flow on Ventilation Parameters
}

\author{
Pricila Mara Novais de Oliveira PT PhD, Armando Augusto Almeida-Junior MD MSc, \\ Celize Cruz Bresciani Almeida PT PhD, Maria Ângela Gonçalves de Oliveira Ribeiro PT PhD, \\ and José Dirceu Ribeiro MD PhD
}

\begin{abstract}
BACKGROUND: Although self-inflating bags are widely used for manual hyperinflation, they do not allow ventilation parameters, such as pressure or volume, to be set. We studied the ventilation performance of neonatal and pediatric self-inflating bags. METHODS: We asked 22 physiotherapists to manually hyperinflate 2 lung models (neonatal and pediatric), using self-inflating bags from 3 manufactures (Hudson, Laerdal, and JG Moriya), with flows of $0,5,10$, and $15 \mathrm{~L} / \mathrm{min}$. A pneumotachograph recorded tidal volume $\left(V_{T}\right)$, peak inspiratory pressure (PIP), peak inspiratory flow (PIF), peak expiratory flow (PEF), and inspiratory time. RESULTS: The $V_{T}$, PIP, and inspiratory time delivered by the Hudson, Laerdal, and JG Moriya bags, in both neonatal and pediatric self-inflating bags, were significantly different $(P<.001)$. The PEF and PIF delivered were different only when using the neonatal self-inflating bags $(P<.001)$. The $V_{T}$, PIP, and PIF delivered with a flow of $0 \mathrm{~L} / \mathrm{min}$ were lower than with $15 \mathrm{~L} / \mathrm{min}(P<.05)$ with all the tested bags, in both the neonatal and pediatric sizes. CONCLUSIONS: The performance of the tested neonatal and pediatric bags varied by manufacturer and oxygen flow. There was an increase in $\mathrm{V}_{\mathrm{T}}, \mathrm{PIP}$, and PIF related to the increase of oxygen flow from $0 \mathrm{~L} / \mathrm{min}$ to $15 \mathrm{~L} / \mathrm{min}$. The neonatal bags showed higher ventilation parameters variation than the pediatric bags. Key words: resuscitation; manual hyperinflation; self-inflating bag; pediatric; respiratory therapy; respiratory function monitor. [Respir Care 2013;58(12):2127-2133. (c) 2013 Daedalus Enterprises]
\end{abstract}

\section{Introduction}

Manual hyperinflation is used to improve secretion clearance and alveolar expansion in mechanically venti-

Pricila Mara Novais de Oliveira PT PhD, Maria Ângela Gonçalves de Oliveira Ribeiro PT PhD, and José Dirceu Ribeiro MD PhD are affiliated with the Department of Pediatrics, Faculty of Medical Sciences, and Armando Augusto Almeida-Junior MD MSc and Celize Cruz Bresciani Almeida PT PhD are affiliated with the Hospital de Clínicas, Universidade Estadual de Campinas, Campinas, São Paulo, Brazil.

This research was partly supported by Coordenação de Aperfeiçoamento de Pessoal de Nível Superior, Brazil.

The authors have disclosed no conflicts of interest.

Correspondence: Pricila Mara Novais de Oliveira PT PhD, Laboratório de Fisiologia Pulmonar, Centro de Investigação em Pediatria, Universidade Estadual de Campinas, Cidade Universitária Zeferino Vaz, Campinas, São Paulo, Brazil 13081-970. E-mail: pricila.mno@gmail.com.

DOI: 4187/respcare.02336 lated patients, and the self-inflating bag is the main device used in manual hyperinflation, but the self-inflating bag does not allow ventilation parameters, such as pressure, volume, or $\mathrm{F}_{\mathrm{IO}_{2}}$, to be set. ${ }^{1-3}$

The American Society for Testing and Materials established standards ${ }^{4}$ for self-inflating bags. However, important physical and functional differences can be observed during cardiopulmonary resuscitation. ${ }^{5-13}$ These differences are among neonatal devices from different manufacturers. Several studies have confirmed that several factors might interfere with the performance of neonatal pulmonary ventilation. ${ }^{5,14,15}$ The factors are professional experience and training, ${ }^{12,16,17}$ lung compliance, ${ }^{18}$ visual feedback, pressure manometer, ${ }^{19}$ number of hands used in bag compression, ${ }^{20,21}$ and the operator's hand size. ${ }^{22}$ All these factors can affect the ventilation parameters of manual hyperinflation. Such variance may impact clinical outcomes.

Few studies have evaluated the functional performance of neonatal self-inflating bags according to oxygen flows, but they assessed only the $\mathrm{F}_{\mathrm{IO}_{2}}{ }^{13,23,24}$ There have been no 
studies of the relationship between self-inflating bags' ventilation parameters with different oxygen flows applied. We studied the performance of neonatal and pediatric selfinflating bags from 3 manufacturers, at different oxygen flows, during manual hyperinflation.

\section{Methods}

\section{Design and Ethics}

The study had a randomized crossover design, and was approved by the University of Campinas ethics committee (408/2008).

\section{Setting}

The study was conducted at the Biomedical Engineering Center of the University of Campinas. We recruited 22 physiotherapists at the Hospital de Clínicas, Universidade Estadual de Campinas, Campinas, São Paulo, Brazil. Eleven of the physiotherapists recruited had clinical experience with bagging critically ill neonates and children, and 11 did not. No prior training was conducted with the subjects. They were instructed to manually hyperinflate with slow inflation and rapid inspiratory pause, followed by fast bag release.

The manual hyperinflation was simulated to set up the respiratory mechanics of a neonate and a pediatric intubated patient in a test lung model (Ventilator Tester 2, Biotek, Winooski, Vermont) (Fig. 1). We used a leak-free and intubated model. Measurements were recorded at different values of pulmonary compliance and resistance, to simulate 2 clinical situations: healthy, normal respiratory mechanics, and restrictive mechanics (decreased pulmonary compliance). The lung resistance was set at $50 \mathrm{~cm} \mathrm{H}_{2} \mathrm{O} /$ $\mathrm{L} / \mathrm{s}$ to simulate a newborn, and at $20 \mathrm{~cm} \mathrm{H}_{2} \mathrm{O} / \mathrm{L} / \mathrm{s}$ to simulate a child. The pulmonary compliance was set at $3 \mathrm{~m} \mathrm{~L} /$ $\mathrm{cm} \mathrm{H}_{2} \mathrm{O}$ to simulate normal compliance in a healthy newborn, at $1 \mathrm{~m} \mathrm{~L} / \mathrm{cm} \mathrm{H}_{2} \mathrm{O}$ to simulate reduced lung compliance in a newborn, at $10 \mathrm{~m} \mathrm{~L} / \mathrm{cm} \mathrm{H}_{2} \mathrm{O}$ to simulate normal compliance in a healthy child, and at $3 \mathrm{~m} \mathrm{~L} / \mathrm{cm} \mathrm{H}_{2} \mathrm{O}$ to simulate reduced lung compliance in a child. These compliance and resistance values were based on a previous study..$^{20}$ The test lung apparatus was calibrated considering the environmental temperature, atmospheric pressure, and relative air humidity before the experiments.

The subjects used only their dominant hand. They were encouraged to ventilate the test lung as they would ventilate a patient, and to rest between tests to avoid fatigue. They were allowed to familiarize themselves with the equipment and environment. The tests were randomized. No visual or verbal feedback was provided during the tests.

After the tests, the subjects underwent a standardized interview about the bags' performance.

\section{QUICK LOOK}

\section{Current knowledge}

Manual hyperinflation is used to improve secretion clearance and alveolar expansion in mechanically ventilated patients. The self-inflating bag is the primary device used in manual hyperinflation, but bagging does not allow good control of ventilation parameters such as pressure, volume, or $\mathrm{F}_{\mathrm{IO}_{2}}$.

\section{What this paper contributes to our knowledge}

The performance of neonatal and pediatric bags varied during manual hyperinflation, by manufacturer and by the oxygen flow applied. There was an increase in tidal volume, peak inspiratory pressure, peak inspiratory flow, and inspiratory time related to the oxygen flow, from 0 to $15 \mathrm{~L} / \mathrm{min}$. The neonatal bags showed greater ventilatory parameter variation than the pediatric bags.

\section{Self-Inflating Bags}

Each subject used 6 new self-inflating bag units. The tested bags were obtained from 3 manufacturers: Hudson RCI/Teleflex Medical (Research Triangle Park, North Carolina), Laerdal Medical (Stavanger, Norway), and JG Moriya (São Paulo, Brazil) (Fig. 2). All the bags were tested with both the neonatal and pediatric models. The bags were connected to a 50-psig source of $100 \%$ oxygen, and flows of $0,5,10$, and $15 \mathrm{~L} / \mathrm{min}$ were delivered. An oxygen reservoir was attached to the unit when the oxygen flow meter was set above $5 \mathrm{~L} / \mathrm{min}$. The pressure relief valve was kept unlocked.

The volumes of the bags tested were: Hudson neonatal $280 \mathrm{~mL}$, Hudson pediatric $500 \mathrm{~mL}$, Laerdal neonatal $240 \mathrm{~mL}$, Laerdal pediatric $500 \mathrm{~mL}$, JG Moriya neonatal $130 \mathrm{~mL}$, and JG Moriya pediatric $250 \mathrm{~mL}$.

The bias was reduced by not telling the subjects what was being investigated. The order of the bag handling, compliance settings, and experience levels of the subjects were randomly assigned. The oxygen flows were used sequentially: $0,5,10$, and $15 \mathrm{~L} / \mathrm{min}$, but the physiotherapists were unaware of this assignment.

Each physiotherapist performed 10 manual hyperinflations with each of the 6 bags (neonatal bag and pediatric bag from 3 manufacturers), with both normal and reduced compliance, and at all 4 flows.

\section{Pneumotachograph}

A sensor $\mathrm{CO}_{2}$ Capnostat (Novametrix, Wallingford, Connecticut) attached to the pneumotachograph $\left(\mathrm{CO}_{2} \mathrm{SMO}^{+}\right.$, 


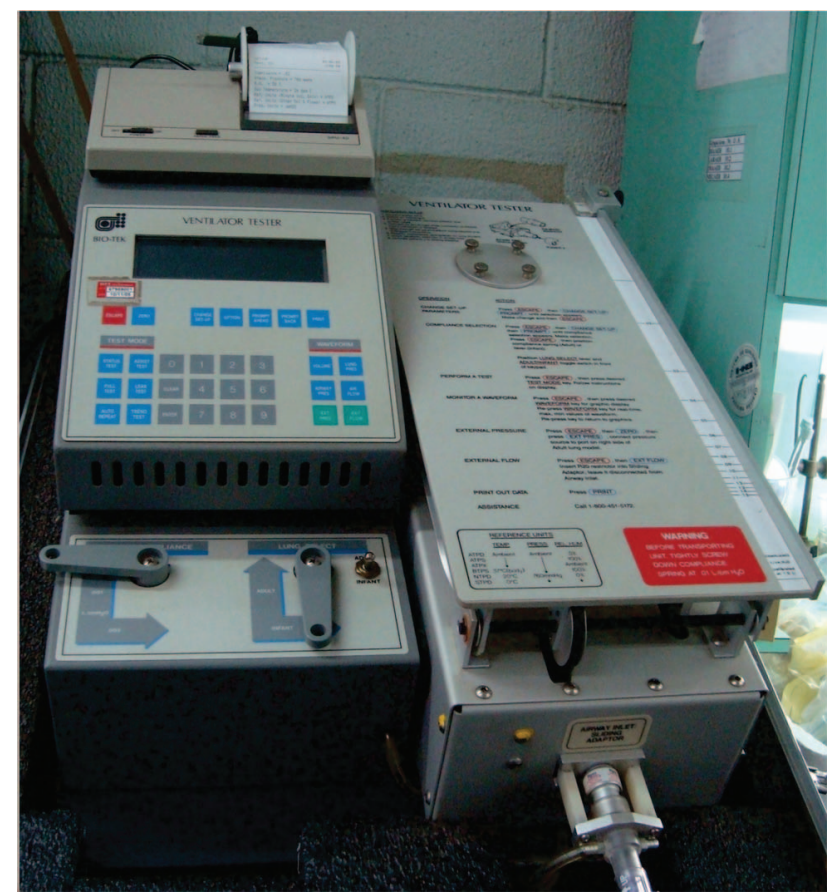

Fig. 1. Test lung model and ventilator tester.

Novametrix, Wallingford, Connecticut) was fitted at the interface between the test lung and the bag, with no important increase in dead space. The signals were recorded by software (Analysis Plus, Novametrix, Wallingford, Connecticut). The physiotherapists were blinded to the pneumotachograph display.

The variables measured were tidal volume $\left(\mathrm{V}_{\mathrm{T}}\right)$, peak inspiratory pressure (PIP), peak expiratory flow (PEF), peak inspiratory flow (PIF), and inspiratory time.

\section{Statistical Analysis}

Statistical analysis was performed with statistics software (SAS 9.1.3, SAS Institute, Cary, North Carolina). The Kolmogorov-Smirnov test was used to assess data distribution, and the data did not have normal distribution, so all the variables were transformed into ranks. We calculated the mean of 10 inflations per test.

The ventilation measurements were compared for the different bag manufacturers and flows with repeated-measures analysis of variance. Then we applied within-subject contrast tests for post hoc analysis. There was no important period effect because the study was in an experimental setting. The results are reported as median and 95\% CI. The significance level for the statistical analysis was $P<.05$.

\section{Results}

$\mathrm{V}_{\mathrm{T}}$, PIP, and inspiratory time delivered by the Hudson, Laerdal, and JG Moriya bags, with both the neonatal and pediatric bags, were statistically different $(P<.001)$. PEF and PIF were different only with the neonatal bags. These data were obtained independently of the flow applied (Table 1). Also, Table 1 presents the within-subjects contrasts.

The PIP delivered ranged from 0 to $46 \mathrm{~cm} \mathrm{H}_{2} \mathrm{O}$ in 528 tests with the neonatal bags. Only one subject provided PIP higher than $40 \mathrm{~cm} \mathrm{H}_{2} \mathrm{O}$, with the Hudson neonatal bag. With the pediatric bags the PIP ranged from 12 to $52 \mathrm{~cm} \mathrm{H}_{2} \mathrm{O}$, and 16 of 22 subjects exceeded $40 \mathrm{~cm} \mathrm{H}_{2} \mathrm{O}$. All these measurements were obtained with the Hudson pediatric bag.

A minimum PIP of $20 \mathrm{~cm} \mathrm{H}_{2} \mathrm{O}$ was not reached in 121 (22.92\%) tests with the neonatal bags, and in 116 (21.97\%) tests with the pediatric bags. Eighteen physiotherapists failed to deliver PIP greater than $20 \mathrm{~cm} \mathrm{H}_{2} \mathrm{O}$ with the neonatal bags, and 19 with the pediatric bags. The PIP values are presented in Table 2 .

$\mathrm{V}_{\mathrm{T}}$, PIP, PIF, and inspiratory time increased with increasing oxygen flow (Fig. 3) and were significantly different at flows of 0 and $15 \mathrm{~L} / \mathrm{min}(P<.001)$. This result was obtained independently of the bag's manufacturer.

The experienced and inexperienced physiotherapists were similar in their overall manual hyperinflation perfor-

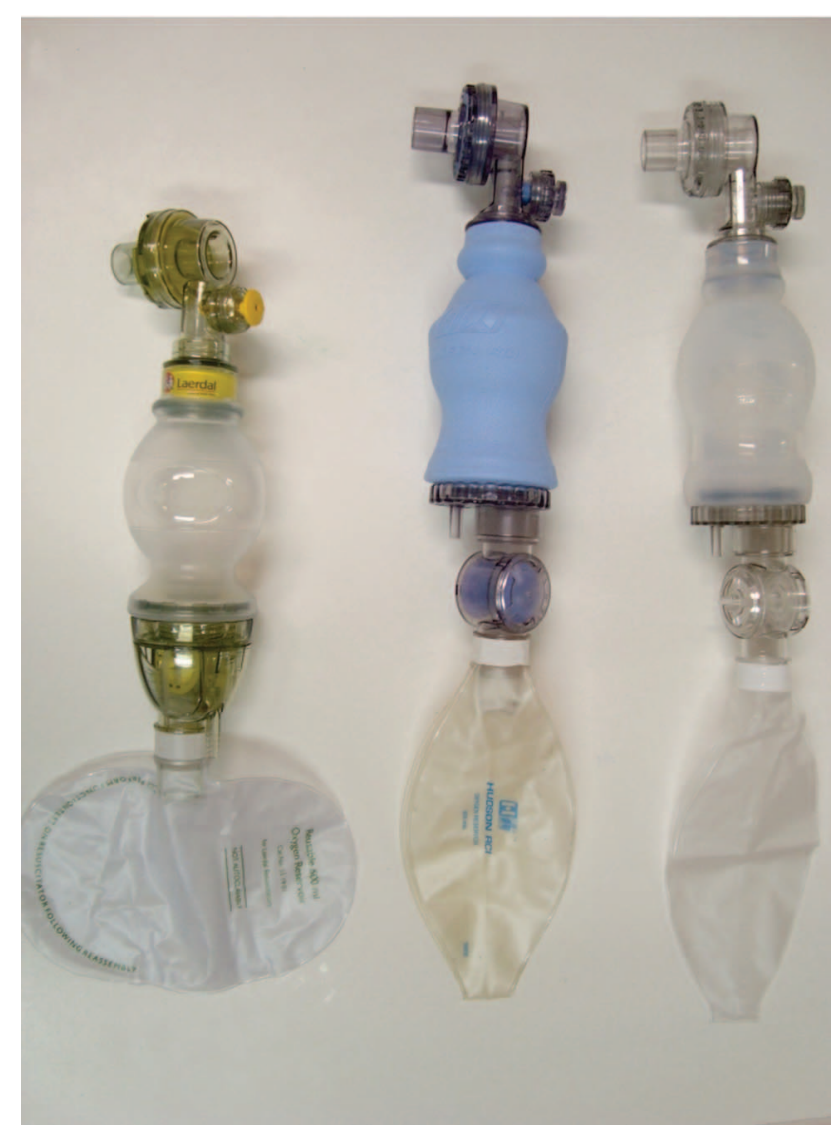

Fig. 2. Neonatal self-inflating bags: Laerdal, Hudson, and JG Moriya. 
Table 1. Ventilation Parameters Delivered by Neonatal and Pediatric Self-Inflating Bags*

\begin{tabular}{|c|c|c|c|c|c|}
\hline & Manufacturer & $\begin{array}{l}\text { Neonatal Bags } \\
\text { median }(95 \% \mathrm{CI})\end{array}$ & $P$ & $\begin{array}{l}\text { Pediatric Bags } \\
\text { median }(95 \% \mathrm{CI})\end{array}$ & $P$ \\
\hline \multirow[t]{3}{*}{ Tidal volume, $\mathrm{mL}$} & Hudson & $41.23(47.2-52.3) \dagger$ & & $169.80(161.7-174.9) \dagger$ & $<.001$ \\
\hline & Laerdal & $41.44(49.6-54.9) \dagger$ & $<.001$ & $146.49(158.9-172.3) \dagger$ & \\
\hline & JG Moriya & $34.76(37.5-42.4) \dagger$ & & $111.19(131.4-146.5) \dagger$ & \\
\hline \multirow[t]{3}{*}{ Peak inspiratory pressure, $\mathrm{cm} \mathrm{H}_{2} \mathrm{O}$} & Hudson & $24.93(25.1-27.2) \dagger$ & & $25.98(28.8-32.4) \dagger$ & $<.001$ \\
\hline & Laerdal & $26.28(25.8-27.5) \dagger$ & $<.001$ & $27.03(26.6-28.6) \dagger$ & \\
\hline & JG Moriya & $21.25(20.0-22.1) \dagger$ & & $22.13(22.4-23.7) \dagger$ & \\
\hline \multirow[t]{3}{*}{ Peak expiratory flow, L/min } & Hudson & $15.74(14.8-15.5) \dagger$ & & $39.33(38.2-40.1)$ & 0.75 \\
\hline & Laerdal & $16.53(15.7-16.5) \dagger$ & $<.001$ & $39.21(38.1-39.8)$ & \\
\hline & JG Moriya & $15.00(13.5-14.5) \dagger$ & & $39.16(37.6-38.7)$ & \\
\hline \multirow[t]{3}{*}{ Peak inspiratory flow, $\mathrm{L} / \mathrm{min}$} & Hudson & $13.18(12.7-13.9) \dagger$ & & $27.03(26.9-29.8)$ & 0.48 \\
\hline & Laerdal & $12.22(11.9-13.2) \dagger$ & $<.001$ & $28.05(27.8-30.7)$ & \\
\hline & JG Moriya & $11.00(11.0-12.3) \dagger$ & & $28.42(27.0-29.6)$ & \\
\hline \multirow[t]{3}{*}{ Inspiratory time, $\mathrm{s}$} & Hudson & $0.41(0.4-0.5) \dagger$ & & $0.67(0.6-0.7) \dagger$ & $<.001$ \\
\hline & Laerdal & $0.51(0.5-0.6) \dagger$ & $<.001$ & $0.75(0.8-0.9) \dagger$ & \\
\hline & JG Moriya & $0.47(0.5-0.6) \dagger$ & & $0.65(0.6-0.7) \dagger$ & \\
\hline
\end{tabular}

Table 2. Delivery of Peak Inspiratory Pressures $<20 \mathrm{~cm} \mathrm{H}_{2} \mathrm{O}$ and $>40 \mathrm{~cm} \mathrm{H}_{2} \mathrm{O}^{*}$

\begin{tabular}{|c|c|c|c|c|}
\hline & \multicolumn{4}{|c|}{$\begin{array}{c}\text { Peak Inspiratory Pressure } \\
\text { no. }(\%)\end{array}$} \\
\hline & \multicolumn{2}{|c|}{$<20 \mathrm{~cm} \mathrm{H}_{2} \mathrm{O}$} & \multicolumn{2}{|c|}{$>40 \mathrm{~cm} \mathrm{H}_{2} \mathrm{O}$} \\
\hline & Neonatal & Pediatric & Neonatal & Pediatric \\
\hline Hudson & $33(6.25)$ & $39(7.39)$ & $4(0.75)$ & $28(5.30)$ \\
\hline Laerdal & $18(3.41)$ & $29(5.49)$ & & \\
\hline JG Moriya & 70 (13.26) & $48(9.10)$ & & \\
\hline Total & $121(22.92)$ & $116(21.97)$ & $4(0.75)$ & $28(5.30)$ \\
\hline
\end{tabular}

* 528 tests with neonatal self-inflating bags, and 528 tests with pediatric self-inflating bags.

mance; the only difference was the highest PIF in the experienced group $(P=.03$ for neonatal bags, $P=.03$ for pediatric bags). The ventilation parameters were different between the normal and reduced compliance settings $(P<.001)$. The subjects delivered a lower $\mathrm{V}_{\mathrm{T}}$, a higher PIP, and a higher PIF in the low compliance setting than in the normal compliance setting (all $P<.001$ ). The comparison of ventilation parameters delivered by experience level and compliance was previously published. ${ }^{16}$

\section{Discussion}

To our knowledge, this is the first study to measure the influence of oxygen flow on physiotherapist performance with 3 neonatal and pediatric bags. We found functional and physical differences between the 3 tested bag models. These differences have been documented during neonatal resuscitation. ${ }^{1,7,25}$ In addition, during neonatal and pediat- ric manual hyperventilation, $\mathrm{V}_{\mathrm{T}}$, PIP, and PIF increased with increased oxygen flow. A few studies of neonatal bag performance have found that $\mathrm{F}_{\mathrm{IO}_{2}}$ varies with the oxygen flow applied, but those studies did not measure $\mathrm{V}_{\mathrm{T}}$, PIP, or PIF. ${ }^{13,23,24}$

In clinical practice the choice of oxygen flow varies according to the patient's oxygenation. However, the North American Neonatal Resuscitation Program recommends a flow of 5-10 $\mathrm{L} / \mathrm{min}$ into the bag inlet when it is connected to a $100 \%$ oxygen source. ${ }^{26}$ Often the manufacturers' recommendations are unknown or not respected. The lack of difference in some ventilation parameters between the flows of 5 and $10 \mathrm{~L} / \mathrm{min}$ demonstrate the safety of using this flow range in daily practice.

The heterogeneous PIPs we found in the present study are in agreement with other studies.9,27 The pressurerelief valve is supposed to open at $35 \mathrm{~cm} \mathrm{H}_{2} \mathrm{O}$ with the Laerdal bag, and at $40 \mathrm{~cm} \mathrm{H}_{2} \mathrm{O}$ with the JG Moriya and Hudson bags we tested; our measured PIPs often exceeded $40 \mathrm{~cm} \mathrm{H} \mathrm{H}_{2} \mathrm{O}$ with the pediatric bags. This fact is even more important during preterm-infant ventilation, which requires more accurate $\mathrm{V}_{\mathrm{T}}$ and PIP. Furthermore, it is intriguing to notice how often the PIP cutoff of $20 \mathrm{~cm} \mathrm{H}_{2} \mathrm{O}$ was not reached. This creates a risk of hypoventilation and inadequate alveolar recruitment during manual hyperinflation.

The bags we tested were suitable for each age group; however, the JG Moriya provided lower $\mathrm{V}_{\mathrm{T}}$ and PIP values than the bags from the other manufacturers. The JG Moriya neonatal bag's PIF was also the lowest among the neonatal bags, so the JG Moriya neonatal bag presumably provides less ventilation. Regardless of international consensus de- 

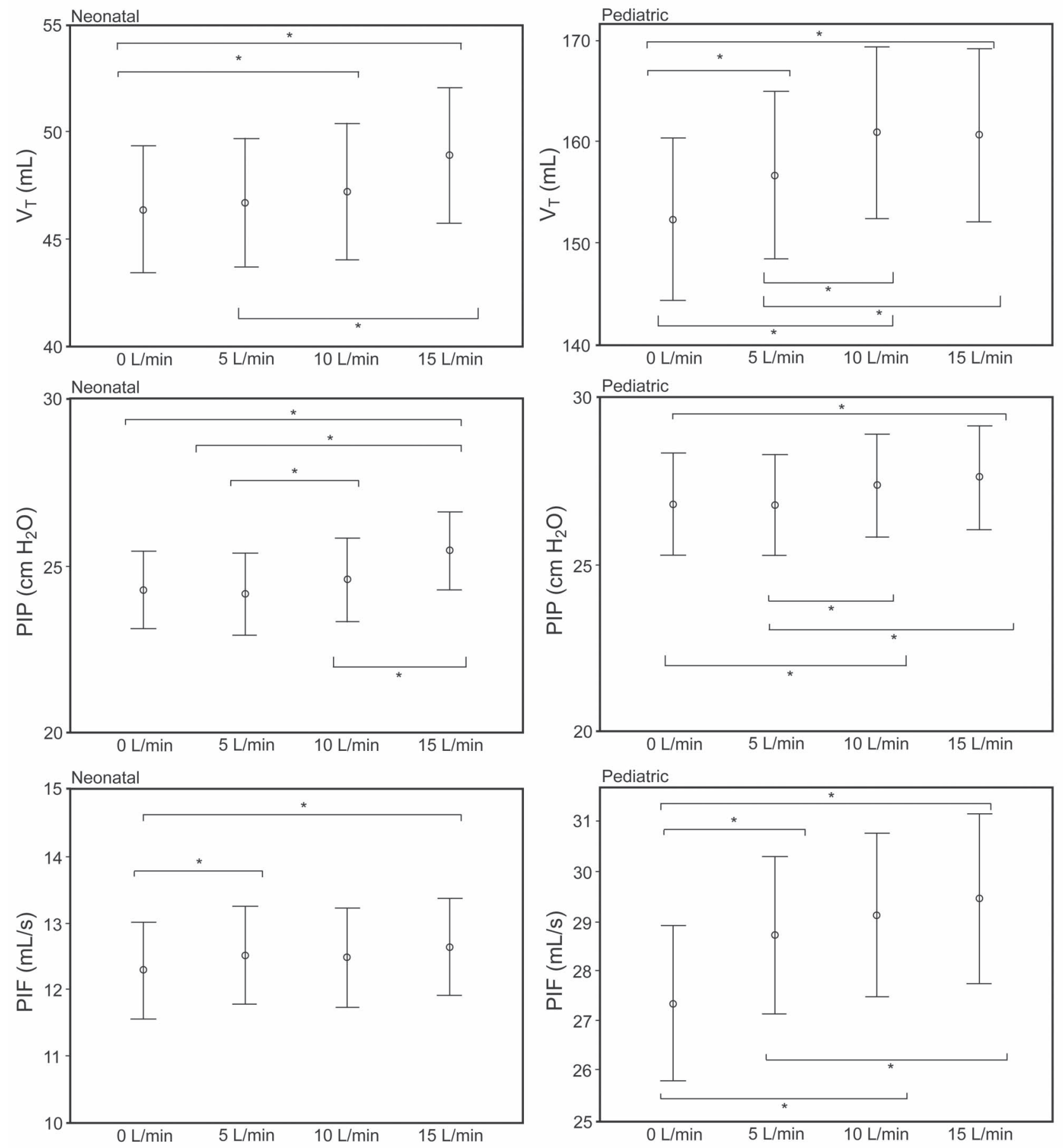

Fig. 3. Tidal volume $\left(\mathrm{V}_{\mathrm{T}}\right)$, peak inspiratory pressure (PIP), and peak inspiratory flow (PIF) from neonatal and pediatric self-inflating resuscitation bags. ${ }^{*} P<.05$.

fining the self-inflating bag as the main instrument for manual ventilation, studies have shown that there is no unanimity in the guidelines for self-inflating bag use in neonatal ventilation. ${ }^{6,8,14}$ Lee et $\mathrm{al}^{28}$ reported that the volumes delivered range widely, and they do not encourage self-inflating bag use for careful and precise ventilation.
The ventilation parameter variation during neonatal manual hyperinflation could be explained by the fact that the neonatal bag $(150 \mathrm{~mL})$ is pressurized faster and also distended, when compared to the pediatric bags. This results in the higher pressures and volumes delivered by neonatal bags. Furthermore, an increased plateau pressure due to 
the low adjusted compliance at the infant setting could reflect in an increased PIP and $\mathrm{V}_{\mathrm{T}}$.

There is a wide range of commercial neonatal and pediatric bags manufactured. The differences in the ventilation performance between those bags could be explained mainly by their physical characteristics, including bag and reservoir volume, valve type, valve resistance, ${ }^{29}$ manufacturing materials, elasticity, density, and bag shape and texture. ${ }^{30}$ To select the appropriate bag for each clinical setting, the clinician should be familiar with the equipment and check it before use. The choice of an inadequate bag for the patient's weight or the underlying disease could be dangerous.

The majority of our subjects (77\%) reported increased resistance squeezing the JG Moriya bag, compared to the Laerdal and Hudson bags. The JG Moriya bag's silicone percentage could explain that higher resistance. Although the devices have similar bag formats, the subjects also described differences in the bags' textures. The Laerdal bag has a shape and texture that provide greater adherence between the bag and the clinician's hand. Mazzolini and Marshall $^{30}$ indicated that differences in bag design and texture affect the $\mathrm{F}_{\mathrm{IO}_{2}}$ delivered by the bag, and that bag shape influences the gripping efficiency and, consequently, the ventilation performance. Bag texture and design can increase the clinician's capacity to perform inflations and prevent the bag from slipping when handled. The bag's manufacturing material can also affect the inflation pressure. ${ }^{18}$ Therefore, the clinician's ability to sense compliance changes could interfere with the ventilation parameters.

Our results were based on an experimental setting. The subjects could not be blinded to the bag used, and we were not able to test the bag's manufacturing materials. Further studies testing different bag manufacturers and evaluating pressures and volumes could contribute to the current results' application. To determine the optimal gas flow for safe manual hyperinflation will require clinical studies.

The self-inflating bag's use for manual ventilation still presents several advantages over other devices. It does not require a continuous gas flow or a power source to be connected, ${ }^{5}$ and bag is portable and easy to use. ${ }^{9,31}$ Based on our results, we recommend that the bag manufacturer and flow applied should be chosen carefully to avoid adverse impacts on clinical outcomes. Although there are several guidelines for resuscitation, recommendations about flow during manual ventilation from the European Respiratory Society or American Thoracic Society were not found.

In agreement with Jones et al, ${ }^{31}$ the present study suggests that bag selection should match the clinician's experience and skills. It is necessary to learn about a bag's physical and functional characteristics and to check the bag before using it. ${ }^{32}$ Until manual hyperinflation clinical evidence is available, we suggest that the clinician use a pneumotachograph or at least a manometer to ensure safe ventilation. Bag use by untrained hands can be dangerous. ${ }^{16}$

\section{Conclusions}

The performance of neonatal and pediatric bags varied during manual hyperinflation, by manufacturer and by oxygen flow applied. $\mathrm{V}_{\mathrm{T}}$, PIP, PIF, and inspiratory time increased with increased oxygen flow. The neonatal bags had higher ventilation parameter variation than the pediatric bags. Our findings should alert clinicians about differences in manual hyperinflation ventilation parameters, in order to conduct safe manual ventilation.

\section{REFERENCES}

1. Finer NN, Barrington KJ, Al-Fadley F, Peters KL. Limitations of self-inflating resuscitators. Pediatrics 1986;77(3):417-20.

2. Goldstein B, Catlin EA, Vetere JM, and Arguin LJ. The role of in-line manometers in minimizing peak and mean airway pressure during hand regulated ventilation of newborn infants. Respir Care 1989;34(1):23-27.

3. Hudson RCI. Lifesaver manual resuscitator-operating manual. Temecula, CA: Hudson RCI; 1993.

4. American Society for Testing and Materials (ASTM). Standard specification for minimum performance and safety requirements for resuscitators intended for use with humans. Designation F920-93. Philadelphia: ASTM; Reapproved 1999.

5. Bennett S, Finer NN, Rich W, Vaucher Y. A comparison of three neonatal resuscitation devices. Resuscitation 2005;67(1):113-18.

6. Dawson JA, Gerber A, Kamlin CO, Davis PG, Morley CJ. Providing PEEP during neonatal resuscitation: which device is best? J Paediatr Child Health 2011;47(10):698-703.

7. Connors R, Kissoon N, Tiffin N, Frewen TC. An evaluation of the physical and functional characteristics of infant resuscitators. Pediatr Emerg Care 1993;9(2):104-107.

8. Finer NN, Rich W, Craft A, Henderson C. Comparison of methods of bag and mask ventilation for neonatal resuscitation. Resuscitation 2001;49(3):299-305.

9. Hussey SG, Ryan CA, Murphy BP. Comparison of three manual ventilation devices using an intubated mannequin. Arch Dis Child Fetal Neonatal 2004;89(6):490-493.

10. Mondolfi AA, Grenier BM, Thompson JE, Bachur RG. Comparison of self-inflating bags with anesthesia bags for bag-mask ventilation in the pediatric emergency department. Pediatr Emerg Care 1997; 13(5):312-16

11. Morley CJ, Dawson JA, Stewart MJ, Hussain F, Davis PG. The effect of a PEEP valve on a Laerdal neonatal self-inflating resuscitation bag. J Paediatr Child Health 2010;46(1-2):51-56.

12. Roehr CC, Kelm M, Fischer HS, Bührer C, Schmalisch G, Proquitté H. Manual ventilation devices in neonatal resuscitation: tidal volume and positive pressure-provision. Resuscitation 2010;81(2):202-205.

13. Thió M, Bhatia R, Dawson JA, Davis PG. Oxygen delivery using neonatal self-inflating resuscitation bags without a reservoir. Arch Dis Child Fetal Neonatal 2010;95(5):315-319.

14. Tracy MB, Klimek J, Coughtrey H, Shingde V, Ponnampalam G, Hinder M, et al. Mask leak in one-person mask ventilation compared to two-person in newborn infant manikin study. Arch Dis Child Fetal Neonatal 2011;96(3):F195-F200. 


\section{Neonatal and Pediatric Manual Hyperinflation: Influence of Oxygen Flow}

15. White JRM, Shugerman R, Brownlee C, Quan L. Performance of advanced resuscitation skills by pediatric house staff. Arch Pediatr Adolesc Med 1998;152(12):1232-1235.

16. Oliveira PMN, Almeida-Junior AA, Almeida CC, Ribeiro MAGO, Ribeiro JD. Does experience influence the performance of neonatal and pediatric manual hyperinflation? Respir Care 2012;57(11): 1908-1913.

17. Resende JG, Menezes CG, Paula AM, Ferreira AC, Zaconeta CA, Silva CA, et al. Evaluation of peak inspiratory pressure and respiratory rate during ventilation of an infant lung model with a selfinflating bag. J Pediatr (Rio J) 2006;82(5):359-364.

18. Kattwinkel J, Stewart C, Walsh B, Gurka M, Paget-Brown A. Responding to compliance changes in a lung model during manual ventilation: perhaps volume, rather than pressure, should be displayed. Pediatrics 2009;123(3):e465-e470.

19. O’Donnell CPF, Davis PG, Lau R, Dargaville PA, Doyle LW, Morley CJ. Neonatal resuscitation 2: an evaluation of manual ventilation devices and face masks. Arch Dis Child Fetal Neonatal 2005; 90(5):F392-F396.

20. Bassani MA, Filho FM, Coppo MRC, Marba STM. Peak pressure and tidal volume are affected by how the neonatal self-inflating bag is handled. J Pediatr (Rio J) 2009;85(3):217-222. Article in Portuguese.

21. Ganga-Zandzou PS, Diependaele JF, Storme L, Riou Y, Klosowski $\mathrm{S}$, Rakza T, et al. [La ventilation à Ambú chez nouveau-né: une simple question de doigté?] Arch Pediatr 1996;3(12):1270-1272. Article in French.

22. Hess D, Spahr C. An evaluation of volumes delivered by selected adult disposable resuscitators: the effects of hand size, number of hands used, and use of disposable medical gloves. Respir Care 1990; 35(9):800-805.

23. Johnston KL, Aziz K. The self-inflating resuscitation bag delivers high oxygen concentrations when used without a reservoir: implications for neonatal resuscitation. Respir Care 2009;54(12): 1665-1670.

24. Reise K, Monkman S, Kirpalani H. The use of the Laerdal infant resuscitator results in the delivery of high oxygen fractions in the absence of a blender. Resuscitation 2009;80(1):120-125.

25. Field D, Milner AD, Hopkin IE. Efficiency of manual resuscitators at birth. Arch Dis Child 1986;61(3):300-302.

26. Health Canada. Family-centered maternity and newborn care: national guidelines. Ottawa: Minister of Public Works and Government Services; 2000:2.19.

27. Oddie S, Wyllie J, Scally A. Use of self-inflating bags for neonatal resuscitation. Resuscitation 2005;67(1):109-112.

28. Lee HM, Cho KH, Choi YH, Yoon SY, Choi YH. Can you deliver accurate tidal volume by manual resuscitator? Emerg Med J 2008; 25(10):632-634.

29. Maa SH, Hung TJ, Hsu KH, alZHsieh YI, Wang KY, Wang CH, Lin HC. Manual hyperinflation improves alveolar recruitment in difficult-to-wean patients. Chest 2005;128(4):2714-2721.

30. Mazzolini DG Jr, Marshall NA. Evaluation of 16 adult disposable manual resuscitators. Respir Care 2004;49(12):1509-1514.

31. Jones AYM, Jones RD, Bacon-Schone J. A comparison of expiratory flow rates in two breathing circuits used for manual hyperinflation of the lungs. Physiotherapy 1991;77:593-597.

32. Hawkes CP, Ryan CA, Dempsey EM. Comparison of the T-piece resuscitator with other neonatal manual ventilation devices: a qualitative review. Resuscitation 2012;83(7):797-802. 